\title{
LITERATURA MARGINAL E CULTURA DA PERIFERIA: UMA ANÁLISE DA OBRA CAPÃO PECADO, DE FERRÉZ
}

\author{
Vanessa Bastos Lima \\ Roberto Henrique Seidel
}

\begin{abstract}
RESUMO: Este trabalho propõe uma discussão do movimento da Literatura Marginal contemporâneo (iniciado na década de 90), que tem como um de seus grandes expoentes o escritor Ferréz. A partir deste trabalho, vamos conhecer e analisar o que intenciona e objetiva o movimento da literatura marginal, conceituar e diferenciar cultura marginal de outras formas de cultura. E, através do estudo do romance Capão pecado, escrito por Ferréz, vamos conhecer um pouco da história do protagonista Rael, discutir e refletir sobre questões como a formação de múltiplas identidades e o descentramento do sujeito na obra em tela, a partir da crise do sujeito pós-moderno, provocado pelo contexto situacional de cada indivíduo.
\end{abstract}

PALAVRAS-CHAVE: Literatura Marginal Contemporânea, Cultura marginal, Ferréz.

ABSTRACT: This paper proposes a discussion on the movement of contemporary "Marginal" literature (started in the 90s), which has as one of its greatest exponents the writer Ferréz. From this work we know and analyze what is the intent and objective of marginal literature movement, conceptualize and differentiate marginal culture from other forms of culture. And, through the study of the novel Capão Pecado, by Ferréz, we know a bit about the stories of the protagonist Rael, discuss and reflect on issues such as the formation of multiple identities and the displacement of the subject in the work Capão Pecado, from the crisis of the subject postmodern, caused by the situational context of each individual.

KEY WORDS: Contemporary Brazilian Marginal Literature, Marginal Culture, Ferréz.

\section{INTRODUÇÃO}

No Brasil nos anos 70, iniciado por autores de classe média alta, surgiu a primeira referência a um tipo de literatura, que recebeu o rótulo genérico de "marginal", porque dizia respeito a obras que foram publicadas de maneira alternativa, representando um momento em que o Brasil estava dominado pela ditadura militar. Em geral, quando se traz a debate o tema "literatura marginal", inicialmente falamos da tentativa de aproximar a poesia dos ${ }^{1}$ aspectos coloquiais da linguagem, de buscar também formas alternativas de produção artística e de fazer frente à alienação provocada pela mídia. Esses eram os objetivos principais da "literatura marginal", ou melhor, da "poesia

1 FERRÉZ, Terrorismo literário. In: FERRÉZ (Org.). Literatura marginal: talentos da escrita periférica. Rio de Janeiro: Agir, 2005. 
marginal" da década de 70. Atualmente, desde os anos 90, o projeto de literatura marginal, que tem como um de seus principais expoentes o escritor Ferréz, apesar de, por um lado, não se distanciar tanto da "literatura marginal" surgida na década de 70 , principalmente nos quesitos combate à alienação e na inauguração de uma nova linguagem nas obras literárias, por outro, os prefácios de Ferréz para a série da Revista Caros Amigos (2001, 2002, 2004), bem como o prefácio à obra coletiva (FERRÉZ, $2005)^{1}$, conforme Luciano Justino (2008, p. 2),

[...] articulam a chamada à literatura a sua colocação num espaço de natureza política que excedem [sic] a questão propriamente estéticoliterária para se situar nas demandas por democracia e por direito à diferença. Eles trazem novas perguntas à literatura: que faz o escritor e o público com a literatura? Para que a literatura tem servido? Quem estabelece o critério de medida? Quem pode escrever? Quem recebe? Em que condições materiais cotidianas?, [perguntas] tão urgentes quanto as questões específicas da Poética enquanto ciência da literatura. Hoje, responder a pergunta espinhosa, e pergunta-matriz da teoria literária, "O que é literatura?", ultrapassa o âmbito [...] da literatura para incluir outros saberes sobre a sociedade e o lugar mesmo do "campo literário" nos sistemas semióticos que formam as culturas.

Desse contexto, é possível depreender um campo nada "confortável” para a reflexão crítica a respeito dessa literatura. O "leitor médio", podemos imaginar, aquele leitor confortavelmente esparramado em sua poltrona, em meio ao seu conforto doméstico é, de pronto, ao entrar em contato com esse novo tipo de literatura, arremessado para uma nova situação, situação essa que coloca em questão todos os seus pressupostos, não só estético-literários, mas principalmente das formas de representação e de mediação cultural. E mais: essa nova postura que desponta do fenômeno da literatura marginal recente questiona o próprio sistema literário, a própria instituição literária, aquilo que já foi definido como o "[...] Cânone Ocidental [que] foi constituído historicamente a partir de critérios em que vogam a autoridade e a universalidade da literatura, [... que é] quase que exclusivamente composto de homens brancos mortos", como bem lembram Machado e Justino (2010, p. 1), na esteira de Pascale Casanova (2002).

Podemos conceituar, a partir do movimento proposto por Férrez, entre outros nomes da literatura contemporânea, como literatura marginal aquela que objetiva dar 
voz aos grupos excluídos da sociedade brasileira. Segundo Érica Peçanha Nascimento, os autores da literatura marginal:

[...] querem denunciar a violência — principalmente a policial -, $\mathrm{o}$ alcoolismo nas famílias, a força do tráfico e a falta de perspectiva dos jovens. Por outro lado, buscam valorizar aspectos positivos da periferia, como solidariedade, o modo de falar $\mathrm{e}$ as gírias características, além das manifestações culturais que estão surgindo nesses lugares (NASCIMENTO, 2009, p. 1).

A literatura marginal vem crescendo, ocupando seu espaço e conquistando, cada vez mais, leitores de diferentes classes sociais, como da classe média, classe alta e, é claro da periferia, pois, como o próprio Ferréz se expressou em sua fala, em palestra proferida por ocasião da Jornada Literária do SESC/BA, em dezembro de 2008, o que se buscava era uma literatura em que o leitor da periferia urbana - paulistana, em primeira instância, mas depois ampliada —, se visse identificado, tanto em termos de linguagem, de temática, quanto em termos ideológicos.

Nesse contexto, a obra Capão pecado, de Ferréz, desponta como um destaque exemplar. Esta obra já se faz presente nos grandes círculos literários do Brasil, circulando, inclusive, nos meios literários internacionais. Capão pecado, obra que será analisada no presente trabalho, tem por principal objetivo denunciar e formar um pensamento crítico a respeito da realidade da periferia brasileira, utilizando-se de elementos da cultura hip-hop ideológica e do rap. Nessa obra também vamos encontrar presentes algumas demandas sociais que estão inseridas no debate sobre pósmodernidade, como por exemplo, a questão da fragmentação identitária do sujeito dito pós-moderno.

Além disso, vamos poder perceber que esta literatura marginal possui uma escrita bem peculiar, como ressalta Érica Peçanha Nascimento (2009, p. 2):

A análise dessa literatura marginal exige que alguns parâmetros críticos sejam revistos, porque os textos destoam do padrão tido como culto, abusando do uso de gírias da periferia e com regras próprias de concordância, plural e ortografia.

Podemos, então, perceber que a literatura marginal, em especial a obra Capão pecado, propõe várias mudanças de paradigmas, em relação à literatura brasileira tradicional, sejam elas relacionadas à linguagem ou ao conteúdo, ou ainda à própria 
percepção da realidade nacional, já que tradicionalmente há um consenso acerca do papel da literatura como de grande importância, efetiva e crucial, na formação das identidades coletivas nacionais. Desponta daí a necessidade de também inquirir acerca do que seria cultural marginal.

\section{QUE CULTURA É ESSA?}

Cultura é uma palavra originada do verbo latino colere, que originalmente significa o cultivo, o cuidado, seja o cultivo do campo — daí, agricultura —,o cuidado com os ancestrais — daí, culto —, seja ainda o cuidado do ensino das novas gerações - daí, puericultura. É claro que, para definir o que seria cultura na contemporaneidade, primeiramente temos que mergulhar no decurso da história, em determinadas épocas na sociedade ocidental, de modo a ter uma ideia mais ampla do que seria cultura.

A filósofa Marilena Chauí (2007), na conferência Cultura e democracia, fez um breve historicização a respeito. Segundo ela, a cultura no século XVIII, no ocidente, representava o mesmo que civilização. Com o iluminismo, a cultura passou a ser o padrão ou o critério de análise para definir o grau de civilização de uma determinada sociedade. Cultura então se torna sinônimo de progresso, passando a ser a "régua" para a avaliação do grau de civilização de um povo ou grupo dado. Informa ainda a autora que, no início da formação da disciplina da antropologia, as sociedades passaram a ser avaliadas segundo a presença ou ausência de elementos pertencentes à cultura européia ocidental e capitalista. Estes elementos eram: o estado, o mercado e a escrita. Daí despontava uma postura etnocêntrica, que validava o imperialismo Europeu. A partir do século XX, de acordo com Chauí (2007, p. 24),

A cultura passa a ser compreendida como o campo em que os sujeitos elaboram símbolos e signos, instituem as práticas, os valores, definem para si próprios o possível e o impossível [...] os valores - o verdadeiro e o falso, o belo e o feio, o justo e o injusto - que instauram a ideia de lei, e portanto, do permitido e do proibido, determinando o sentido da vida e da morte e das relações entre o sagrado e o profano.

Diferenças entre cultura dominante, cultura popular e cultura marginal 
Falar de cultura dominante é falar do processo de relações sociais que divide a sociedade em classes: a dos dominantes - que representa os dirigentes e a elite econômica, a qual dita os padrões culturais; e a dos dominados ou subalternos daqueles que representam a camada desprivilegiada e de baixa renda da sociedade e que tem sua produção cultual discriminada, ou lhe é ditada pela classe dominante uma cultura a ser consumida. É a chamada classe dominante que detém a maior parte dos meios de produção cultural, por ser detentora de um grande acúmulo de capital. Por isso, é esta classe social que construiu a cultura dominante, dotada de erudição e tida como padrão em relação aos outros tipos de culturas, como em relação, por exemplo, à cultura popular.

O termo cultura popular é dotado de muitas acepções e carrega com ele algumas ambiguidades; porém, analisando algumas definições dicionarizadas do verbete, dentre as primeiras acepções, encontrar-se-á algo que referenda este tipo de cultura como aquela produzida pelo "povo". Entende-se aí povo enquanto a totalidade de uma sociedade ou região, como o conjunto total dos participantes de uma sociedade, excluindo-se, portanto, os grupos dirigentes e participantes da elite econômica. Desta forma, cultura popular seria algo negativamente visto como o conjunto de práticas culturais inferiores, vindas de camadas econômicas baixas de uma determinada sociedade, opondo-se à noção de cultura dominante anteriormente explicitada.

Podemos então, a partir dessa contextualização, perceber duas abordagens possíveis para o termo cultura popular. Esta pode ser tanto uma expressão de práticas culturais autônomas, com sua lógica própria, e à qual se opõe a cultura letrada, quanto uma expressão de práticas culturais criadas por aqueles que detêm o poder econômico para o consumo da população das classes subalternas da sociedade.

Além da cultura erudita e popular, há também a cultura marginal, que é aquela que não se enquadra dentro dos padrões tradicionais de se produzir cultura. É uma arte do conflito e da provocação, sempre buscando novas formas de expressão e novos olhares num mundo esteticamente voltado para a cultura do belo e do politicamente correto. A cultura marginal tenta aproximar a arte com aspectos coloquiais que possam refletir uma espécie de realidade dotada de crueza e de desigualdade, dando voz a quem não tem voz e incentivando o pensamento crítico. 
No Brasil, pode-se considerar que a cultura marginal foi, de fato, instaurada após a Semana de Arte Moderna, sem ter sido feito uso do termo. Mário de Andrade, na obra Macunaíma, possibilitou a reflexão a respeito da realidade brasileira, através de seus personagens. Macunaíma foi uma obra que fugiu dos padrões românticos e parnasianos valorizados em épocas anteriores. Durante a Semana de Arte Moderna de 22, diversos artistas buscaram romper com os padrões e criar uma arte própria em que se retratasse a realidade brasileira.

Atualmente, os maiores representantes da cultura marginal são os rappers. $\mathrm{Na}$ literatura, o que diferencia essa nova geração da literatura marginal daquela da década de 70 é o fato de que a produção dessa nova literatura não mais é feita por pessoas sensibilizadas com a realidade da periferia brasileira, mas por pessoas que vivem essa realidade e escrevem sobre ela; portanto, o locus da enunciação é outro. Comumente são destacados Paulo Lins, autor do livro Cidade de Deus; Férrez, autor de Capão pecado e Manual prático do ódio, entre outras obras; e Alexandre Buzzo, autor de vários poemas, crônicas e textos; todos eles autores que se enquadram dentro da estética da literatura marginal.

\section{Cultura, mídia e massificação}

$\mathrm{Na}$ sociedade ocidental contemporânea, os valores culturais estão intimamente ligados à mídia, ao julgamento de valor que esta faz de cada manifestação cultural. A mídia é que determina o que devemos ler, ouvir, comprar ou ver. E este processo denominamos como massificação. O fenômeno da massificação dificulta o processo de democratização dos meios de produções culturais, e é justamente contra a massificação, a alienação, que vem lutando o movimento da literatura marginal.

Ferréz, na tentativa de democratizar o espaço literário e com a intenção de inserir a literatura em espaços abertos de maneira alternativa, realizou uma parceria com a revista de circulação nacional Caros Amigos. Três volumes em edições especiais foram publicados dando espaço para a manifestação cultural de vários escritores de literatura marginal. O principal objetivo desta parceria foi transformar esse veículo midiático em um espaço cultural democrático. Ferréz é um autor que entende a carência de políticas sociais democráticas e, pensando nisso, em seus livros, a exemplo de Capão pecado, ele 
dá espaço para a manifestação de rappers compositores de hip-hop, e poetas da literatura marginal. Em Capão pecado, no intervalo de cada parte do livro, podemos encontrar manifestações da cultura produzida na periferia dos grandes centros, a exemplo da cidade de São Paulo.

Entre a primeira e a segunda parte do livro, o autor apelidado como Ratão vai manifestar-se dizendo:

Sou apenas mais um guerreiro quilombola do exército de ZUMBI contrariando tudo e todos, com metas diferentes, planos loucos, mas ideais gigantescos.

Contra a elite e a favor do meu povo. Contra alienados e a favor dos revolucionários.

"Zé povinho" fica mordido, não entende, aponta julga e condena, mais aí RAP é meu escudo, é minha arma, é questão de vida ou morte.

Não me deixo levar, a Rede Globo até tenta, mas não vai me enganar. Não tô a fim de ver merda de Sandy e Júnior o dia inteiro na TV cantando suas músicas sem conteúdo e ganhando dinheiro com a miséria do povo.

Me fazer de cego, não to a fim, de aturar esta porcaria que domina a mídia televisiva e escrita (RATÃO, 2000 apud FERRÉZ, 2005, p. 41).

Por intermédio da definição de cultura de massa, a partir de Max Horkheimer e Theodor Adorno, explicitada no artigo de Antonio Hohlfeldt (2007, p. 48), entende-se que a mesma é produto de empreendedores capitalistas dirigida para a alienação e reificação das massas, com enorme lucratividade para tais realizadores, na medida em que guia-se pelo gosto das massas, acostumando-se a produtos de baixa qualidade em detrimento das verdadeiras obras do espírito humano, ou seja, a cultura de massa restringe-se à categoria de bem de consumo. A cultura de massa está fortemente vinculada às sociedades tecnológicas, e é veiculada pelos meios de comunicação midiáticos, como a TV.

Neste acima citado, a alienação e a massificação da mídia são duramente criticadas, na personificação dos cantores Sandy e Júnior, tendo como ícone midiático máximo a Rede Globo que, segundo o autor, é a representação dos ideais de elite. Além da crítica aos veículos midiáticos televisivos e escritos, Ratão deixa explícito que tipo de cultura ele representa: a cultura daqueles que querem sair do campo da invisibilidade, ultrapassar os muros da periferia; ele propõe uma revolução. Mas, que revolução seria essa? Uma revolução capaz de derrubar os muros imaginários e culturais que separam a “cultura popular" feita pelo povo da periferia, de outras culturas. Está tácito que há uma 
divisão social não acidental, que é reconhecida por Maquiavel em $o$ Príncipe, que diz: "toda cidade é dividida pelo desejo dos grandes de oprimir e comandar e o desejo do povo de não ser oprimido nem comandado" (MAQUIAVEL, apud CHAUÍ, 2007, p. 27). E é justamente contra esta força opressora dos "grandes", que a literatura marginal vem batalhando.

Abrindo a terceira parte do livro Capão pecado está o texto "Se eu quero, eu posso, eu sou", que diz:

Mas e aí? Fazer o quê? Como diz o TIM:

- $\mathrm{Ah}$ ! Se o mundo inteiro me pudesse ouvir...

Mas como todos nós sabemos que é muito difícil fazer com que o mundo inteiro nos ouça, nós mandamos um toque daqui, do nosso canto [...] (OUTRAVERSÃO, apud FÉRREZ, 2005, p. 69).

Neste trecho vemos ser reforçada a ideia de que "a voz da periferia", o grito dos que estão à margem mas que também produzem arte e literatura, seja escutada, mesmo sabendo da dificuldade, a qual é representada pela frase do cantor e compositor Tim Maia.

Ainda sobre a divisão cultural em cultura dominante e cultura popular, Marilena Chauí vai dizer que:

O lugar da cultura dominante é bastante claro: é aquele a partir do qual se legitima o exercício da exploração econômica, da dominação política e da exclusão social. Mas esse lugar também torna mais nítida a cultura popular como aquilo que é elaborado pelas classes populares e, em particular, pela classe trabalhadora, segundo o que se faz no pólo da dominação, ou seja, como repetição ou como contestação, dependendo das condições históricas e das formas populares de organização (CHAUÍ, 2007, p. 29).

Em sendo a literatura marginal um movimento artístico e cultural realizado pela classe popular e trabalhadora, por orgânicos da periferia, ela tem sua história de luta pautada na contestação dos moldes da cultura imposta pela classe dominante. Cultura imposta essa que é também conhecida por massificação, conforme Chauí (2007, p. 29) ainda o coloca: “[...] é preciso levar em conta como a divisão cultural tende a ser ocultada e, por esse motivo, reforçada com o surgimento da cultura de massa ou da indústria cultural". Ela ainda vai explicar como os bens culturais são divididos. Primeiramente são separadas as obras "raras e caras", destinadas ao público mais abastado, a chamada elite cultural; e há as obras "baratas e comuns", destinadas ao povo 
(à massa), aos menos privilegiados. Dessa forma, a indústria cultural separa a elite "culta" da massa "inculta". Portanto, não se deve ter a ilusão de que todos têm direitos iguais de acesso à cultura e aos bens culturais. Esta ilusão. Inclusive, é derrubada por Férrez e seus companheiros de literatura marginal. A divisão cultural, assim como a divisão em classes ${ }^{1}$, existe e, por isso, a literatura marginal visa lutar por seu espaço de representação artística.

Além de dividir a cultura de maneira preconceituosa e injusta, a indústria cultural faz com que a classe média e alta tenham nojo e medo da cultura de seu próprio país, da cultura principalmente produzida na periferia. No texto "Talvez seja melhor seguir a honestidade", que está em Capão pecado iniciando a quarta parte do livro, percebemos a denúncia da realidade vivenciada na favela:

Bom, falarei sobre um assunto embaçado: é o seguinte, tá ligado; o crime que é noticiado no rádio, jornal, televisão, é sempre diretamente ligado à miséria. Por quê? Porque pondo os pés no chão é bruta a nossa realidade.

[...] Aí como sou preto, vem o preconceito racial, policiais despreparados agredindo, espancando [...] neste momento você lê, muitas famílias pedem socorro. Você já cresce no meio do veneno e chega uma hora em que o desespero é total (NEGREDO, apud FERRÉZ, 2005, p. 109).

Por conta de deflagrar uma realidade de pobreza e na qual a violência está sempre presente, na mídia impera a noção generalizada de que a miséria é causa da violência. Daí, como aponta Marilena Chauí, vemos
as classes ditas desfavorecidas sendo consideradas potencialmente violentas e criminosas. Este é um preconceito que atinge profundamente os habitantes das favelas, estigmatizados não só pelas classes média e dominante, mas pelos próprios dominados: a cidade olha a favela como uma realidade patológica, uma doença, uma praga, um quisto, uma calamidade pública (CHAUÍ, 2007, p. 60).

Complementando as palavras de Marilena Chauí, a favela é vista como um lugar "sem jeito", de onde nada de bom pode ser esperado, muito menos arte e literatura. No entanto, Ferréz e seus companheiros de movimento literário vêm provar o contrário, como podemos ler no texto "C. R campo de Guerra da nova era”, que inicia a última parte de Capão pecado: "O foco de esperança está nos muros grafitados, nos bailes feitos nas quadras das escolas, nos [sic] pipas no céu, e nos movimentos em prol da 
cultura, desde fanzines até as organizações que resistem aqui” (GARRET, apud FERRÉZ, 2005, p. 133).

A "esperança" da periferia em aparecer nos jornais de maneira positiva é a arte e os projetos artísticos como a literatura marginal, já que sabemos que a periferia tem sim sua cultura, sendo esta muitas vezes desprezada e/ou meramente ignorada. E que cultura é essa? É a cultura de rua, dos guetos, produzida na favela, e é através dela que se pode conhecer um pouco do cotidiano da periferia das grandes cidades, conhecer seus escritos, sua literatura, seu grito.

\section{ADENTRANDO NA HISTÓRIA DE CAPÃO PECADO}

A obra Capão Pecado toma como espaço Capão Redondo ${ }^{1}$, que é uma favela como muitas espalhadas pelas grandes cidades do Brasil. Lá, diariamente, os moradores presenciam cenas de violência, tanto entre os próprios moradores (entre facções rivais), como também entre os moradores e a polícia. Mas, apesar de estar envolta em um contexto de violência e miséria, existe em vários momentos uma relação de solidariedade e união, como por exemplo, quando alguém da comunidade sofre as consequências da violência a que estão expostos diariamente.

Por ser uma obra pertencente ao projeto de literatura marginal, encabeçado por Ferréz, ela vai mostrar que, como relata Loïc Wacquant (apud BAUMAN, 2003, p. 108): "ser pobre numa sociedade rica implica em ter o status de uma anomalia social e ser privado de controle de sua representação e identidade coletiva" - processo denominado pelo autor de privação simbólica, que torna os habitantes da favela, do gueto, verdadeiros párias. Dentro de uma sociedade excludente, há os estigmas e as denominações de caráter pejorativo, que as denominadas por Bauman (2003) como “comunidades poderosas", impõem aos moradores da periferia, mesmo os que não queiram ter sua identidade construída e representada apenas pelo olhar do "outro".

Em Capão pecado vamos conhecer o outro lado da história da periferia, que muitas vezes não podemos conhecer através da mídia televisiva e jornalística. 


\section{A trajetória de Rael}

Rael, personagem principal de Capão pecado, é um jovem filho único de pais analfabetos, um garoto de origem pobre que, quando criança, mudou-se com a família para o bairro de Capão Redondo. Rael é um garoto que faz amizades facilmente, educado e calmo, bem recebido na casa de seus amigos, pois: "Seu aspecto calmo sempre agradava às mães dos colegas: gordinho, cabelo encaracolado, e óculos grandes e pretos [...]. Tudo isso lhe conferia a aparência de um pequeno cdf' (FÉRREZ, 2005, p. 16). Gostava de ler e de ver seriados na televisão, era do tipo que se esforçava muito no trabalho. Inicialmente, trabalhava em uma padaria, "Atendia aos clientes como sempre com muita educação e um sorriso de orelha a orelha" (Idem, p. 44). Nos fins de semana tomava curso de datilografia. Rael era um filho bastante dedicado à sua mãe, pois separava uma parte do dinheiro que ganhava no trabalho para ajudá-la. Com os amigos era prestativo, companheiro e grato. E, apesar de não se envolver com atividades ilícitas ou praticar atos de violência, ele tinha seu cotidiano marcado por ela: "Suas perdas eram constantes e aparentemente intermináveis; o primeiro amigo a morrer lhe causou um baque e tanto, mas a morte dos outros dois fora menos desgastante [...]" (Idem, p. 18).

Rael, por presenciar muitas histórias trágicas, acabava, assim, como os demais moradores do Capão Redondo, por se acostumar a ver seus entes queridos ou amigos serem mortos pela polícia, ou por traficantes, ou ainda pelo vício das drogas. Depois de passar algum tempo trabalhando na padaria, Rael consegue emprego em uma metalúrgica, na qual Paula, a namorada de seu amigo Matcherros, trabalha. O personagem Rael até então, apesar de residir em um bairro violento, levava sua vida pacatamente; papear com os amigos, jogar videogame, dar umas voltas pelo bairro, ler e ver seus seriados e desenhos prediletos.

Quando começa a trabalhar na mesma empresa em que trabalhava Paula, namorada de seu melhor amigo, Rael, com a convivência e amizade, acaba apaixonando-se por ela. Inicialmente, consciente do mal que poderia the acontecer por ter se apaixonado pela namorada do amigo, ele tenta resistir a esse sentimento, até porque ele sabe que a primeira lei da favela é: "nunca cante a mina de um aliado, senão vai subir" (Idem, p. 66). 
Rael, por vezes, pensa em se entregar ao sentimento que tem por Paula, e fica confuso, como podemos perceber no trecho: "Não sabia o que faria de sua vida; não sabia se pensava na consideração pelo amigo ou naquele estranho amor.” (Idem, p. 73). Apesar da indecisão, Rael acaba entregando-se ao amor que sente por Paula. Paula e Rael acabam indo viver juntos em uma casinha no fundo da metalúrgica, cedida por seu patrão, seu Oscar, e têm um filho. Tudo parecia perfeito até que

Chegou em casa cedo aquela noite. Alguma coisa estava errada. Aquele dia o marcaria como o mais desgraçado de sua vida. Ele nem conseguiu ler o bilhete por inteiro, caiu no chão chorando. Tinha sido abandonado repentina e inexplicavelmente. Um bilhete uma troca cruel, ele chorava e queria sua mulher e seu filho de volta, mas nada restava na casa, nenhum móvel nenhum utensílio, nada. (Idem, p. 137).

É daí em diante que o leitor de Capão pecado vai abandonar a visão romântica do garoto da periferia, que vive feliz em sua comunidade e poderia um dia triunfar, ser reconhecido, e ir morar fora da favela. Rael entra em crise, quando ao mesmo tempo descobre que foi traído e abandonado por sua esposa; arquiteta um plano para matar o amante de Paula, seu chefe Oscar. Rael acaba indo para a prisão e lá é morto.

Ao entrar em crise, Rael acaba por agir de maneira diferente do esperado da sua personalidade, descrita no início do livro, rapaz calmo e educado, que até então nunca tinha praticado nenhum ato considerado ilícito ou violento contra ninguém. Anthony Giddens vai dizer que:

Uma "crise" soa como uma grande perturbação, ou ameaça de perturbação, num determinado estado de coisas — o significado original da palavra, proveniente do contexto médico, referindo uma fase de uma doença que oferecia perigo à vida. Nas condições sociais modernas, porém as crises tornam-se mais ou menos endêmicas, tanto ao nível individual, quanto ao coletivo. Até certo ponto, efeito retórico — num sistema aberto à mudança, contínua e profunda, surgem muitas circunstâncias que podem ser facilmente consideradas como crises, em vários níveis. Existe uma "crise" sempre que as atividades relativas a importantes objetivos na vida de um indivíduo ou de uma coletividade repentinamente aparecem inadequadas (GIDDENS, 2002, p. 171).

$\mathrm{O}$ ato de violência cometido por Rael não possibilita mais que ele continue sendo visto pelo leitor como um personagem romântico e, portanto, linear. Por intermédio da crise, provocada pelas decepções vivenciadas por Rael, ele acaba mudando seu comportamento, passando de um extremo para outro, igualando-se a Burgos, 
personagem que pertence ao mundo do crime. Então, a partir deste momento de revolta e crise de Rael, há uma divisão entre o Rael visto como herói e "bom moço" da história, e o Rael bêbado, homicida, que morre na prisão, e acaba terminando como tantos outros moradores da periferia. Ele passa a ser mais um na multidão de casos daqueles que inicialmente tentam mudar de vida, "subir na vida" e ter uma espécie de "conformismo autoritário". A respeito disto, Eric Fromm vai explicar que:

O indivíduo deixa de ser ele mesmo; adota o tipo de personalidade que lhe é oferecido pelos padrões culturais; e portanto, torna-se exatamente igual a todos os outros e ao que os outros esperam que ele seja... esse mecanismo pode ser comparado à coloração que os animais assumem. Eles parecem tão semelhantes ao seu entorno que só podem ser distinguidos dele com grande dificuldade (FROMM, apud GIDDENS, 2002, p. 177).

Rael representa o modelo de bom pai, bom filho e bom marido, trabalhador, que se contenta com a vida que leva. Ele era, até o momento de sua crise, um indivíduo dentro dos padrões culturais e do que esperam que ele seja. Mas Ferréz buscou quebrar esse padrão seguido pelo personagem, quando o fez revoltar-se e não aceitar mais a sua nova realidade de vida. E, ao colocar-se à revelia dos fatos, da traição e do abandono, Rael acaba caindo em mais um ciclo de exclusão. Ele já fazia parte de um ciclo de exclusão apenas pelo fato de viver na periferia; mas quando comete um crime e vai para o presídio, ele entra no rol dos excluídos que moram na periferia, cometeram atos ilícitos e não aceitáveis pela sociedade. Então, podemos dizer que o protagonista pertence a grupos de que, segundo Dench (apud BAUMAN, 2003), não se pode escapar, pois o pertencimento de um indivíduo a um grupo é marcado pelas coletividades mais fortes, sobre as mais fracas, ou seja, Rael pertencia ao grupo dos que vivem na periferia, que é uma coletividade maior, sem deixar sua subjetividade e particularidade como ser humano. Depois ele passa a pertencer ao grupo dos presidiários, que representa uma coletividade mais ampla, coletividade essa subdividida de acordo com os tipos de crimes que cada um cometeu.

\section{CONSIDERAÇÕES FINAIS}

"A capoeira não vem mais, agora reagimos com a palavra, porque pouca coisa mudou, principalmente para nós” (FERRÉZ, 2005, p. 9). Assim inicia Ferréz seu 
manifesto em Terrorismo literário. Ele avisa que além de outras manifestações artísticas como a capoeira, há décadas atrás marginalizada, agora chegou a vez de demonstrar que a periferia não irá se calar, mostrar sua voz através do poder da palavra escrita, mesmo que muitos digam: "Cala boca, negro e pobre aqui não tem vez! Cala a boca! Cala a boca uma porra, agora a gente fala, agora a gente canta, e na moral agora a gente escreve" (Idem, 2005, p. 9). Ferréz vai mostrar toda a revolta e ferocidade ao responder àqueles que não consideram a literatura feita por moradores da periferia como arte.

Estar na periferia, significa estar distante de um lugar que podemos denominar como "centro". Nas grandes cidades, quem está na periferia são os moradores da favela, das ruas, dos morros. São aqueles que historicamente pertencem à classe desprivilegiada da população, são os que estão à margem da parcela da sociedade que controla a economia, a política, que detêm um alto poder de consumo e que controlam a mídia e os meios de propagação da arte e da cultura.

E o que propõem aqueles que fazem parte do movimento da literatura marginal?

Propõem a problematizarão da tradição literária, propõem também o questionamento de critérios de hierarquização e valor cultural, propõem o alargamento daquilo que se considera tradição literária, para que novas obras que representam novos e múltiplos tipos culturais, e de identidade, sejam absorvidas e lhes seja atribuído o valor merecido, sem compará-las aos modelos literários passadistas e homogêneos.

Já que estamos longe de termos uma cultura homogênea, e já que temos uma sociedade multiétnica, e, portanto, plural, como podemos na literatura possuir uma tradição hegemônica, que só inclui escritores da classe média e alta, em sua maioria, e que primam apenas por um tipo de linguagem culta e refinada, pela erudição?

A literatura marginal objetiva uma releitura da tradição literária no Brasil, a qual substitua o singular pelo plural. A literatura marginal, como revela Ferréz, não intenciona seguir o padrão “[...] não é ser o empregado que vira o patrão, não, isso não, aqui ninguém quer humilhar, pagar migalhas nem pensar, nós sabemos a dor por recebêlas" (Idem, 2005, p. 9). Esse movimento de literatura não quer o espaço ocupado por “outras literaturas", ele reivindica o seu espaço e, acima de tudo, a democratização cultural, para que haja espaço para todas as culturas. 
A literatura é um espaço privilegiado para manifestações de caráter social, devido à legitimidade artística que ela representa; portanto, faz-se necessário cada vez mais democratizar o fazer e o espaço literário, para que novas manifestações, assim como a literatura marginal, possam ter seu lugar.

\section{REFERENNCIAS}

BAUMAN, Zygmunt. Comunidade a busca por segurança no mundo atual. Rio de Janeiro: Jorge Zahar, 2003.

BIOGRAFIA do escritor Ferréz. Disponível em: <http://www.astormentas.com/biografia.aspx ?tp=\&id =Ferréz.htm>. Acesso em: 25 out. 2009.

CASANOVA, Pascale. A república mundial das letras. São Paulo: Ateliê Editorial, 2002.

CHAUÍ, Marilena. Cultura e democracia. Salvador: Governo da Bahia, Secretaria de Cultura, 2007. Coleção Cultura é o quê?

FERRÉZ. Manifesto de abertura: Literatura Marginal. Revista Caros Amigos - A cultura na periferia: ato 1. São Paulo: Ed. Casa Amarela, 2001.

FERRÉZ. Capão pecado. Rio de Janeiro: Objetiva, 2005.

FERRÉZ. Terrorismo literário. In: FERRÉZ. (Org.). Literatura marginal: talentos da escrita periférica. Rio de Janeiro: Agir, 2005, p. 9-14.

GANDINI, Sérgio Luiz; WOITOWICZ, Karina Jans. (Org.). Noções básicas de folkcomunicação. São Paulo: UEPG, 2007.

GIDDENS, Anthony. Modernidade e identidade. Rio de Janeiro: Jorge Zahar, 2002.

JUSTINO, Luciano Barbosa. Novos estatutos de memória na literatura brasileira contemporânea: os "marginais". In: Anais Eletrônicos do Encontro Nacional da ABRALIC. São Paulo: ABRALIC, 2008. Disponível em: $<$ http://www.abralic.org/anais/cong2008/AnaisOnline/simposios/pdf/007/ LUCIANO_JUSTINO.pdf $>$. Acesso em: 15 mar. 2010.

MACHADO, Anny Karine Matias Novaes; JUSTINO, Luciano Barbosa. Literatura: espaço de lutas antagônicas? In: Anais eletrônicos da ANPUH. Disponível em: <http://www.anpuhpb.org/anais_xiii_eeph/textos/ST\%2017\%20-

$\% 20$ Anny $\% 20$ Karine $\% 20$ Matias\%20Novaes\%20Machado\%20e\%20Luciano\%20Barbo sa\%20Justino\%20TC.PDF>. Acesso em: 15 mar. 2010. 
MARX, Karl; ENGELS, Friedrich. Manifesto do Partido Comunista. Disponível em: $<$ http://ateus.net/ebooks/geral/marx_manifesto_comunista.pdf.htm>. Acesso em: 2 nov. 2009.

NASCIMENTO, Érica Peçanha. Literatura marginal. Disponível em: $<$ http://recantodasletras.uol. com.br/resenhasdelivros/132050.htm>. Acesso em: 13 abr. 2009.

REVISTA Caros Amigos. Literatura marginal: ato I. Mar. 2001.

REVISTA Caros Amigos. Literatura marginal: ato II. Mar. 2002.

REVISTA Caros Amigos. Literatura marginal: ato III. Mar. 2004.

RECEBIDO EM: 04 de maio de 2011

APROVADO EM: 06 de junho de 2011 